\title{
A QUESTÃO NEGRA NO MUNDO MODERNO ${ }^{1}$
}

\section{THE BLACK QUESTION IN THE MODERN WORLD}

\author{
Nkolo Foé2
}

\begin{abstract}
RESUMO: O objetivo deste artigo é uma análise da Questão Negra na história moderna. A compreensão radical desta questão exige uma apreensão clara das mudanças do capitalismo moderno. O modo de produção capitalista prioriza os homens e as raças de acordo com seus talentos e suas contribuições intelectuais ou tecnicas à economia. Para legitimar a escravidão, o capitalismo usa o argumento da "inferioridade congênita" do Negro. Este argumento reaparece cada vez que o capitalismo tenta de acelerar o processo de acumulação ou de superar uma crise sistêmica. É o que aconteceu durante os últimos anos, apesar do fato de que as lutas nacionais de libertação e as independências africanas conseguiram afirmar a humanidade dos Negros e a historicidade das sociedades africanas. Os movimentos de reforma ou de revolução social na África apareceram como portadores de um ideal de transformação qualitativa da Condição Negra em nome da retomada da iniciativa histórica. Isso implicou a exigência de ruptura e de saída do Império. Mas os movimentos conservadores como a Negritude e o Pós-colonialismo encararam o destino do Negro no seio do Império. Este artigo tenta esclarecer os termos do confronto que envolve os níveis gnosiológicos (ex.: a questão da razão ou da intuição relacionada à mente negra); metodológicos (ex.: a questão da hermenêutica e da inteligibilidade do real); epistemológicos (ex.: a questão da historia, da geografia e da etnologia); ontológicos (ex.: a questão da flexibilidade ou não do ser); culturais (ex.: a questão da mestiçagem); políticos (ex.: a questão do ajustamento ou de resistência à ordem do mundo).
\end{abstract}

Palavras-chave: Negritude; Pós-colonialismo; Emancipação, Iniciativa histórica.

SUMMARY: The objective of this article is an analysis of the Black Question in modern history. The radical understanding of this question demands a clear apprehension of the changes of the modern capitalism. The way of capitalist production prioritizes the men and the races in accordance with its intellectual talents and its contributions or techniques to the economy. To legitimize the slavery, the capitalism uses the argument of the "congenital inferiority" of the Black. This argument reappears each time that the capitalism tries to speed up the accumulation process or to surpass a systemic crisis. It is what you happen during the last few years, although the fact of that the national fights of release and African independences had obtained to affirm the humanity of the Blacks and the historicity of the African societies. The movements of reform or social revolution in Africa had appeared as carrying of an ideal of qualitative transformation of the Black Condition on behalf of the retaken one of the historical initiative. This implied the requirement of rupture and exit of the Empire. But the movement's conservatives as the Negritude and After-colonialism had faced the destination of the Black in the Empire. This article tries to clarify the terms of the confrontation that involves the gnosiological levels (former.: the question of the reason or the intuition related to the black mind); methodological (former.: the question of the hermeneutics of the Real); epistemological (former.: the question of history, geography and the ethnologic); ontological (former.: the question of the flexibility or not of the being); cultural (former.: the question of the mestization); politicians (former.: the question of the adjustment or resistance to the order of the world).

Word-key: Negritude; After-colonialism; Emancipation, historical Initiative.

\footnotetext{
${ }^{1}$ Este artigo revisto retoma as idéias essenciais desenvolvidas na palestra proferida pelo Dr. Prof. Nkolo Foé na abertura do IV Colóquio Internacional Saberes e Práticas na Universidade Federal do Estado da Bahia (UFBA) realizado entre 25 e 28 de outubro de 2010.

2 Professor da Ecole Normale Supérieure, Université de Yaoundé 1 - Camarões.
} 


\section{Introdução: A Universalidade da Questão Negra}

Pela duração (5 séculos), a intensidade e a crueldade dos métodos utilizados pelos opressores, a servidão dos Negros foi o crime o mais hediondo dos tempos modernos. Mas, apesar do horror, este crime nunca foi punido. Pelo contrário, a Europa está pedindo à África que reconheça os beneficios da colonização. Ao mesmo tempo, o artigo 4 da lei de 23 feveiro 2005 da Assembléia Nacional Francesa determina que se de ênfase ao papel positivo da colonização nos currículos. Atitudes deste tipo ilumina bem a condição do Negro no mundo moderno, desde o século dezoito, pelo menos.

\section{A Questão Negra: uma Criação do Universalismo Moderno}

A questão surge das primeiras consequências da própria modernidade. Esta questão se colocou porque o pertencimento do Negro à espécie humana não era uma evidência. É a mesma coisa com a possessão da razão, da capacidade de criar a cultura e da civilização. Estas considerações foram feitas no cerne do Iluminismo como evidenciado por filósofos desta época, David Hume e Immanuel Kant por exemplo, que afirmaram a inferioridade congênita do Negro.

A leitura do Tratado sobre os caracteres nacionais é interessante. Neste livro, Hume diz que a raça negra é inferior a raça branca. Segundo Hume, não existe nenhuma nação desta raça que seja civilizada e nenhum indivíduo ilustre por suas ações ou suas capacidades intelectuais ou morais. Por ele os negros ignoram tudo o que tem a ver com inteligência: a manufatura, a arte, a ciência. $O$ autor vai mais longe: não existe nenhuma comparação entre a barbárie do negro mais evoluído e a barbárie do branco mais vulgar. É que o branco revela um potencial do progresso indefinido enquanto o negro se caracteriza pela estagnação. Isso significa que ao longo do tempo e do espaço, a diferença entre essas raças é permanente e invariável. Hume continua dizendo que é a própria natureza que explica tais diferenças. É que o objetivo da natureza era diferenciar as raças humanas e estabelecer uma hierarquia rigorosa entre elas. Preventivamente, Hume recusa o argumento histórico-social que tenta explicar a imbecilidade do negro pela servidão. Ele fornece um exemplo: os negros livres não mostram nenhum indício de inteligência superior em comparação ao indício dos negros escravizados. Sobre um negro da Jamaica que teria talento, Hume afirma a mediocridade das obras daquela pessoa, semelhante a um papagaio que apenas balbucia algumas palavras aprendidas (HUME, 1999, p. 207, nota 12). 
Sobre essas questões, Kant concorda com Hume e parece severo. Kant diz que "Os negros da África não possuem, por natureza, nenhum sentimento que se eleve acima do ridículo" (KANT, 1993, p. 75). Chamando a autoridade de Hume, ele afirma que

Dentre os milhões de pretos que foram deportados de seus países, não obstante muitos deles terem sido postos em liberdade, não se encontrou um único sequer que apresentasse algo grandioso na arte ou na ciência, ou em qualquer outra aptidão; já entre os brancos, constantemente arrojam-se aqueles que, saídos da plebe mais baixa, adquirem no mundo certo prestígio, por força de dons excelentes. Tão essencial é a diferença entre essas duas raças humanas, que parece ser tão grande em relação às capacidades mentais quanto à diferença de cores. A religião do fetiche, tão difundida entre eles, talvez seja uma espécie de idolatria, que se aprofunda tanto no ridículo quanto parece possível à natureza humana. A pluma de um pássaro, o chifre de uma vaca, uma concha, ou qualquer outra coisa ordinária, tão logo seja consagrada por algumas palavras, tornam-se objeto de adoração e invocação nos esconjuros (KANT, 1993, p. 76)

A filosofia de Kant era cheia de preconceitos. E nas relações com os negros ele recomenda o uso do chicote: "Os negros são muito vaidosos, mas à sua própria maneira, e tão matraqueadores, que se deve dispersá-los a pauladas.” (KANT, 1993, pp. 75-76).

Sobre esta questão, devemos notar a especificidade do caso de Voltaire na medida em que seu ponto de vista parece contraditório. Inicialmente, Voltaire aceita a fraternidade e a igualdade entre as raças negra e branca, quando ele afirma a identidade de todas as raças do mundo. Em nome deste princípio fundamental, Voltaire condena veementemente a escravidão e a opressão que sofrem os negros. Mas de maneira surpreendente o mesmo Voltaire tenta justificar a escravidão do negro quando ele diz que a Europa compra "os escravos domésticos nos países dos negros” porque este povo trafica seus próprios filhos. Voltaire não compreende a razão porque a Europa é censurada quando ela pratica este negócio. Porque, segundo Voltaire, "um povo que trafica seus filhos é mais condenável que o comprador”. De qualquer maneira, este negócio demonstra a superioridade absoluta da Europa. E Voltaire conclui que "aquele que se entrega a um mestre nasceu para ter um". (VOLTAIRE, 1963, p. 807).

Esta conclusão merece uma observação. Tentar convencer o povo vencido da África que ele é responsável pela sua própria servidão parece um fenômeno único na história. Por exemplo, é possível aplicar aquele princípio à França vencida dos anos 1940? Nós devemos nos lembrar que a França destes anos é a nação deitada e humilhada que convidou o ocupante alemão a estabelecer um leadership europeu e mundial. É esta França indigna que entregou os seus próprios filhos aos crematórios e às fábricas de guerra do carrasco nazista. Para julgar a França, não podemos ignorar a resistência e o heroísmo das pessoas como Charles De Gaulle. Por causa do heroísmo da resistência, não podemos 
aplicar à França de joelhos, a máxima de Voltaire: "Aquele que se entrega a um mestre nasceu para ter um”. Então com as resistências africanas, porque aplicar esta máxima à África? O pós-colonialismo (Cf. ETOUNGA MANGUELE, 1993, p. 20) está errado quando ele acredita nestes tipos de preconceitos herdados da escravatura e do colonialismo.

O Iluminismo decretou a inferioridade dos negros para legitimar a servidão. As diferenças dos caracteres com os brancos são permanentes e imutáveis porque os negros são condenados a se tornarem escravos dos Europeus. Voltaire tenta explicar a inferioridade dos negros. Primeiro, ele enfatiza a inferioridade física. Voltaire descreve o negro com um nariz chato, os olhos redondos, os lábios sempre espessos, os cabelos em forma de lã. Segundo, Voltaire enfatiza a inferioridade intelectual. Ele afirma que a medida da inteligência mostra enormes diferenças entre o povo branco e o povo negro. Assim, como exemplos, Voltaire diz que os africanos não são capazes de concentrar a atenção; eles são incapazes de calcular. Enfim, esta raça não parece criada para suportar nem os benefícios nem os abusos da filosofia da Europa. O retrato do negro feito aqui mostra uma ligação forte entre as características físicas e as qualidades morais e intelectuais. $O$ preconceito comum era que a beleza física condiciona a boa qualidade da mente, como o explica Do Espírito das Leis. Montesquieu que relata os preconceitos da época dele escreve que "é tão natural considerar que é a cor que constitui a essência da humanidade, que os povos da Ásia, que fazem eunucos, privam sempre os negros da relação que eles têm conosco de uma maneira mais acentuada. Pode-se julgar da cor da pele pela dos cabelos, que, entre os Egípcios, os melhores filósofos do mundo, eram de tão grande importância, que mandavam matar todos os homens ruivos que lhes caíam nas mãos”. De um ponto de vista moral, os homens da época de Montesquieu estavam convencidos que Deus, que é um ser muito sábio, não podia introduzir uma alma boa num corpo completamente negro. De um ponto de vista intelectual, Montesquieu aponta a estupidez dos negros que, segundo ele, não são capazes de tirar proveito dos metais preciosos dos seus países: "Uma prova de que os negros não têm senso comum é que dão mais importância a um colar de vidro do que ao ouro, fato que, entre as nações policiadas, é de tão grande conseqüência". Durante a época de Montesquieu, a cor preta justificava plenamente a escravidão dos povos da África. Então, porque lamentar estes seres que, além de ser preto, têm um nariz achatado. A verdade é que nesta época não se teve certeza da humanidade dos negros. Mas é interessante ver como o capitalismo recusa a humanidade a um grupo humano ou a uma raça para justificar a escravidão. É que a economia da Europa precisava de novos animais de carga para substituir os Índios da América exterminados. É 
porque Montesquieu diz que: "Se eu tivesse que defender o direito que tivemos de escravizar os negros, eis o que diria: "Tendo os povos da Europa exterminados os da América, tiveram que escravizar os da África, a fim de utilizá-los no desbravamento de tantas terras. O açúcar seria muito caro se não se cultivasse a planta que o produz por intermédio de escravos". (MONTESQUIEU, 1979, livro X V, cap. 1).

Assim, desde o Iluminismo até a época de Hegel e de Gobineau, o ser negro foi excluído do gênero humano comum e mesmo da História. O discurso do Presidente da Republica Francesa Nicolas Sarkozy na Universidade Cheikh Anta Diop de Dakar (Senegal) em 2007, é a prova que os preconceitos da época do Iluminismo não desapareceram com Hume, Kant, Voltaire, etc. Segundo o Sr. Nicolas Sarkozy: “O drama da África é que o homem africano ainda não entrou o bastante na história”. O retrato que Sr. Sarkozy fez do camponês africano é curioso. Por ele, desde há milênios, o camponês da África vive com as estações, sendo seu único ideal ficar em harmonia com a natureza. O Sr. Sarkozy continua dizendo que o africano só conhece o eterno recomeço do tempo. O que caracteriza este tempo é a repetição sem fim dos mesmos gestos e das mesmas palavras. Neste imaginário, todas as coisas recomeçam sempre e não existe nenhum lugar ou nenhuma oportunidade para a aventura humana ou para o progresso. Porque a natureza rege tudo, o homem da África foge da angústia da história que pressiona o homem moderno. Assim, ele só fica imóvel dentro de uma ordem imutável onde tudo parece já escrito desde sempre. Nunca o homem busca sair da repetição para inventar um destino próprio. O Sr. Sarkozy conclui seu discurso dizendo que o maior desafio da África é entrar mais na História mundial. (In COURS NOUVEAU, 2008, pp. 75-89).

$\mathrm{Na}$ África, a reação da elite intelectual ao discurso do Presidente francês foi vigorosa. Foi uma oportunidade excelente para discutir várias questões em relação, por exemplo, com o lugar do negro e da África na história universal. (Cf. COURS NOUVEAU, 2008).

Mas, inclusive na minha própria reação (NKOLO FOE, 2008, pp. 70-75), a questão decisiva não foi apontada seriamente. Esta questão está relacionada com a maneira como o capitalismo imobiliza a história dos povos vencidos ou a maneira como este regime obriga as nações exploradas a executar as tarefas repetitivas. A exploração dos vencidos não é possível sem a imobilização da cultura indígena e sem a saída do vencido de sua historia anterior. É o sentido do que Aimé Césaire chamou de a perda da iniciativa histórica. 


\section{A Perspectiva da Negritude e da Etnofilosofia: A Ratificação Ideológica da Exclusão do Negro na História}

Numa situação de dominação, o capitalismo se caracteriza pela especialização das tarefas. É assim que este regime expulsa os povos vencidos da história universal e os relega na particularidade. A Negritude e a Etnofilosofia não foram capazes de apreender este aspecto do capitalismo. É a razão porque essas ideologias ratificaram a visão do mundo que resultava da estruturação étnica e racial do universo pelo capitalismo. A Negritude e a Etnofilosofia refletem de um ponto de vista cultural, a particularidade característica de um universo dominado, explorado e excluído da historia universal. É o sentido da rejeição da razão e do universalismo, o elogio da intuição, da emoção, do instinto. Todo isso justifica o culto da diferença e a reivindicação da essência negra.

De maneira profunda, podemos dizer que a Negritude e a Etnofilosofia são o sintoma de uma crise cultural profunda ou um índice de que o povo africano já perdeu a iniciativa histórica. A particularidade significa que a cultura do povo vencido fala doravante dos abismos obscuros da história. Desta posição, o vencido se revela incapaz de dialectizar, isso significa de transcender o imediato para encontrar Outro. A derrota histórica leva o vencido a conversar miseravelmente na estreiteza e na obscuridade de seu ser amorfo, com ele mesmo, segundo o modo da repetição e da tautologia.

Deste ponto de vista, o que dizia Buffon, que cito, é muito interessante. Porque o retrato que ele fez dos negros da África mostra como o capitalismo usa as diferenças psicológicas, étnicas e culturais para dominar os povos. Segundo Buffon, de todos os negros, os senegaleses são os melhores por causa de um caráter formado pela submissão e pela docilidade. Buffon diz que esses Negros são os mais fáceis de disciplinar e também os mais adequados para os serviços domésticos. Além de serem altos, os Bambaras, do Mali, são conhecidos por terem uma mentalidade de ladrões. Já o povo dos Aradas é perito no trabalho dos campos, enquanto os Congos são vistos como hábeis pescadores, apesar de serem rápidos para fugir.

É desta maneira que o capitalismo distribui os papéis e os lugares conformes à constituição psicológica e cultural de cada súdito; ao mesmo tempo, o capitalismo atribui a cada grupo étnico ou racial uma tarefa definida e específica, de acordo com a habilidade de cada um. 
A Negritude é uma doutrina da servidão (Towa, 1971a). Por exemplo, Senghor rejeita o ideal de resistência e aceita o cargo e as funções definidos pelo capitalismo para o negro. $\mathrm{Na}$ doutrina de Senghor a civilização do universo aparece como uma orquestra panhumana dotada de uma seção para o mestre, a Europa, o branco, e uma seção rítmica para o negro.

A teoria da força vital de TEMPELS e a caracterologia étnica (Cf. GRIEGER, 1961) refletem esta visão do mundo. A força vital é um legado do século dezenove enraizado nas categorias relacionadas com o sistema de "epistemologias paracientíficas" (Piaget). Devemos considerar que o vitalismo nasceu como alternativa à biologia e à psicologia científica no final do século dezenove. Por exemplo, encontramos este conceito fundamental no cerne do bergsonismo. Assim Henri Bergson apreende a ciência e o conceito como os fenômenos incapazes de expressar a realidade em mudança da vida e do psiquismo. Segundo Bergson, a ciência é especializada para fazer as leis adequadas para apreender conceitualmente o universo das coisas sólidas e o tempo geométrico. Enquanto, o universo das coisas fluidas e movediças deve ser apreendido além do conceito, das leis cientificas e da razão abstrata. Então, Bergson diz que nós precisamos da intuição que é a faculdade a mais adequada para esta tarefa especifica.

Há aqui uma oposição radical entre esta última faculdade e o conhecimento racional. Segundo Piaget, essa oposição pode ser explicada porque a metafísica do século dezenove concebia a matéria como uma sedimentação do impulso vital. Ao mesmo tempo, a inteligência racional e a ciência parecem ser as formas de solidificação resultada da ação sobre os sólidos. Para dizer a mesma coisa, a ciência parece ser uma decomposição da consciência intuitiva, explicada pelas necessidades utilitárias. (PIAGET, 1967, p. 29-30).

Já na Alemanha, a doutrina do impulso vital se misturou com o romantismo para dar um conteúdo irracional ao nacionalismo. O nacionalismo alemão precisava deste ingrediente para radicalizar a oposição ao intelectualismo francês e inglês. $O$ problema fundamental aqui era o de uma definição estética e mística da nação.

Misturada com a religiosidade luterana, o romantismo místico alemão entende que o espírito divino se manifesta na história pelas criações únicas, originais, irredutíveis em forma das individualidades coletivas chamadas nações. As nações são vistas como uma encarnação da Volksgeist (Espírito ou Alma do povo) (VERMEIL, 1952, p. 131). Essa entidade mística explica as teorias da sociedade orgânica e do gênio nacional 
específico. Aqui nós temos uma visão cósmica, religiosa e estética da comunidade política e nacional. Essa visão implica que a sociedade, a história, a cultura e as instituições políticas e econômicas dos povos não são produtos dos homens históricos, mas a obra misteriosa de uma entidade por cima da história e da razão humana.

A partir desta visão mística da história e da evolução dos povos, Frobenius opõe o espírito dos povos do Ocidente (França e Inglaterra) ao espírito alemão (Deutschheit) (FROBENIUS, 1940, 1952). A oposição aqui significa uma contradição fundamental, irreversível entre dois etno-tipos diferentes: é por um lado um etno-tipo enraizado no intelectualismo, no realismo e no materialismo; por outro lado, é um etno-tipo enraizado na mística do leste, no êxtase, na nostalgia, na fé, no maravilhoso, na emoção, na intuição mística, no pensamento vegetativo, no sentimento vital. (FROBENIUS, 1940, p. 87; 1952, p. 25).

A Negritude e a Etnofilosofia aceitaram essa visão do mundo sem interrogar seriamente o conteúdo econômico e social dela. Porque o problema fundamental da Alemanha era o de todos os povos atrasados no desenvolvimento moderno: a confrontação com a dominação das forças políticas e culturais colossais do capitalismo.

As razões do sentimento vital podem ser buscadas no caráter polarizado de um mundo partilhado entre um centro moderno e hegemônico e uma periferia tradicional ou semi-tradicional oprimida. O que caracteriza a sociedade capitalista moderna é a velocidade das mudanças; ao mesmo tempo, as estruturas econômicas, sociais, culturais e ideológicas do capitalismo reduzem cada dia mais o espaço da tradição no mundo inteiro. O sentimento vital resulta das dificuldades de adaptação às mudanças repentinas deste sistema econômico em rápida expansão.

Podemos concluir que o sentimento vital descrito pela etnologia e filosofia expressa a angústia existencial dos povos atrasados, incompletamente integrados ao sistema, mas empurrados pelas forças econômicas, políticas, militares e culturais do capitalismo moderno. $\mathrm{Na}$ verdade, os teóricos da alma africana e da alma alemã tentaram expressar em termos obscuros e místicos essa distorção ou assimetria fundamental que resultava de uma integração imperfeita a um sistema econômico, político e cultural desestabilizador. O Romantismo - e mais tarde a caracterologia étnica - é a expressão cultural de uma economia dualista. Devemos insistir sobre o feito em que a etno-tipologia divide o mundo entre os perpetuosos e extrovertidos por um lado e os introvertidos e flutuantes por outro 
lado (SENGHOR, 1977, pp. 122-127). Tudo isso aparece como o reflexo ideológico de uma polaridade que opõe dois mundos antagonistas em conflito brutal: o mundo industrializado e opressor do norte e o mundo agrário e oprimido do sul. Segundo a descrição feita por Senghor, os povos agrários e flutuantes remetem aos bantos, latinos americanos, mediterrâneos e eslavos. Esses povos têm também outra característica comum: todos eles foram dominados pelo Ocidente burguês e branco.

Já, a escravatura colocou de maneira brutal o problema de acesso de todos os povos à ciência e à técnica. A resposta do Código negro espanhol era clara, porque este código diz que:

\begin{abstract}
Uma das culpas maiores da Constituição da Ilha espanhola é permitir que os negros livres e os escravos pratiquem todas as técnicas e todas as profissões; eles não devem roubar este recurso que pertence à população branca. Se esse recurso aumenta para o povo negro, ele favorecerá o crescimento e o desenvolvimento deles e, ao mesmo tempo, o decréscimo progressivo dos mestres deles. Assim o trabalho e a atividade serão o legado dos negros, a ociosidade, a indolência e vaidade, o legado dos brancos (In SALA-MOLINS, 1992, p. 115)
\end{abstract}

Durante a época do imperialismo ao início de século XX, Oswald Spengler aponta "a traição contra a técnica" como o fator maior do declínio do Ocidente (SPENGLER, 1958, p. 177). Este pensador explica a superioridade do Ocidente desde o século dezenove nos planos militares, econômicos e políticos pelo monopólio da indústria. Assim, o destino do resto do mundo era absorver os produtos da indústria da Europa e da América do norte. Spengler mostra que a política colonial foi para abrir os novos mercados e para procurar as matérias primas. Assim, havia carvão em outros lugares, mas só os engenheiros brancos sabiam como explorá-lo. Os brancos eram os únicos e exclusivos possuidores não só das matérias primas, mas também dos métodos e dos cérebros qualificados e preparados espiritualmente, intelectualmente e tecnicamente para valorizá-las. (SPENGLER, 1958, pp. 172-173).

O problema com Spengler é que ele considera a educação científica e técnica como uma questão étnica e racial. Os essencialistas da época de Spengler parecem convencidos de que para os indígenas da África, da Ásia e da America Latina a ciência e a técnica não podem constituir uma necessidade interior, porque só o branco "pensa, sente e vive dessa forma" (SPENGLER, 1958, p. 177). Spengler afirma também que só para os povos europeus, a cultura científica e técnica é uma necessidade espiritual. Por isso, os povos brancos não devem compartilhar esse privilégio da raça superior com os povos da Ásia, da 
África e da América Latina. Compartilhar o segredo da potência com os povos não brancos é, de acordo com ele, uma traição trágica contra o próprio espírito do Ocidente.

Quando os ideólogos da Negritude aceitaram os princípios da caracterologia étnica, eles esqueceram esses desafios políticos e econômicos. O Negro que eles consideraram nos relembra o escravo de Aristóteles. É um homem instintivo, privado do intelecto e da razão. Referindo-se a mente do preto, a Negritude falava da "razão sensível", no cerne da doutrina da força vital desde a perspectiva de Leo V. Frobenius e Placide Tempels.

Esta visão do mundo foi aceita porque a Negritude e a Etnofilosofia recusavam a idéia fundamental do sujeito da história, racional e portador de um projeto global de emancipação. Devemos nos lembrar que a Negritude rejeitou o princípio sábio e heróico de independência nacional na África, a partir do momento que ela considerou o nacionalismo como uma velha espingarda. O senghorismo percebia as independências nacionais como um mito perigoso só capaz de alimentar um nacionalismo anárquico. $\mathrm{O}$ Império aparecia como o único horizonte para Senghor que declarou que falar de independência é como raciocinar com a cabeça em baixo e os pés em cima; isto não é raciocinar, é colocar um falso problema, visto que o lugar natural para o negro era um vasto Império regido pelo Ocidente.

A mestiçagem e o hibridismo resultam diretamente dessa visão imperial do mundo. Existe hoje uma convergência marcante entre as doutrinas da Negritude e do pósmodernismo. Da mesma maneira que o Império de Senghor, o Império pós-moderno aparece como o lugar por excelência da mestiçagem e do hibridismo dos seres, segundo as conclusões da antropologia da globalização. (NEGRI, 2000; APPADURAI, 2001). Assim, no contexto do pós-modernismo e do pós-colonialismo, a Condição Negra tem uma forma particular, adaptada às exigências do mercado e do consumismo.

\section{A Perspectiva Pós-Colonial}

Como já visto, a abordagem pós-colonial estende, em vários aspectos, a doutrina da Negritude, mesmo se ela resulta de maneira direta do pós-modernismo. Em relação à questão negra e à sua condição no mundo, a perspectiva pós-colonial implica alguns problemas importantes que merecem uma análise cuidadosa de um ponto de vista metodológico, epistemológico e político. 


\section{A ruptura do vínculo entre o poder de explicação e o poder de transformação} do mundo

A questão de ruptura do laço entre o poder de explicação do mundo e a capacidade de transformar este mundo me parece crucial.

Do pós-modernismo, o pós-colonialismo herdou a idéia de que o mundo não é para conhecer ou para explicar, mas só para interpretar. Michel Maffesoli propõe o conceito importante de socialidade pós-moderna como alternativa ao social moderno. Ele considera a socialidade pós-moderna como uma categoria polissêmica, uma realidade plural que integra o caos dos símbolos, dos valores, dos afetos, das emoções (MAFFESOLI 2002a, p. 194).

Maffesoli (2002a, pp. 194-195) concorda com Jean-François Lyotard (1974, pp. 129, 274, 277) e Gilles Deleuze (1980, pp. 46-47) na recusa da idéia de lei social ou histórica. O mundo de símbolos parece além da toda tentativa de explicação e de inteligibilidade.

Segundo Maffesoli, a compreensão dos fenômenos sociais de nossa época implica a mudança radical de perspectiva que significa: não explicar ou criticar, mas compreender e admitir (MAFFESOLI 2002a, p. 22). Maffesoli, afirma que além das representações filosóficas ou políticas, é preciso apresentar fenomenologicamente o que é. Desta maneira, o pós-modernismo e o pós-colonialismo coincidem com os princípios fundamentais do positivismo conservador. Boaventura de Sousa Santos exprime esse positivismo quando ele diz que "o senso comum" pós-moderno "aceita o que existe tal como existe; privilegia a ação que não produza rupturas significativas no real. Por último, o senso comum é retórico e metafórico; não ensina, persuade” (SANTOS, 2010a, p. 90).

Podemos colocar estes pontos de vista em relação com a mestiçagem e o hibridismo. A doutrina da mestiçagem não pretende contestar a ordem assimétrica do mundo regido pelo capitalismo, o colonialismo e o imperialismo. As mudanças de identidades que ela implica, constituem uma forma de capitulação, de submissão e de adaptação às forças invencíveis do Império. Então, ao invés de tentar compreender o mundo e dominar as leis que o constituem, devemos simplesmente interpretar a realidade, mesmo se esta realidade parece intolerável e se nossa condição presente seja indigna. O universo da mestiçagem é miserável porque ele proíbe a saída do Império e da escravidão. No contexto do Império, a mestiçagem e o hibridismo podem ser considerados como uma 
prisão doce onde a liberdade se confunde com a liberdade de negociar e de consumir, mas num estatuto de inferioridade e de impotência radicais.

Existe um vínculo forte entre estas questões e outras questões metodológicas, epistemológicas e políticas colocadas pela hermenêutica.

\section{A Hermenêutica, a semiologização da realidade social, a Etnologia e recusa do projeto de emancipação}

A hermenêutica tem como proposta fundamental a idéia de que o essencial no estudo de uma cultura é a apreensão das figuras simbólicas que são os mitos e mistérios. Esta abordagem corresponde à uma recusa de toda forma de inteligibilidade dos sistemas de pensamento racional, das leis sociais, dos princípios econômicos, das regras que regem as instituições políticas.

A primeira observação que podemos fazer aqui é que a hermenêutica se compreende bem num contexto geral de semiologização da realidade social. Carlos Nelson Coutinho diz que

O privilegio (quase monopólio) concedido às dimensões simbólicas na vida social acaba por reduzi-la, no limite, ou à pura discursividade ("tudo é discurso") ou ao domínio do signo e/ou à instauração abusiva de hiper-realidade (COUTINHO, 2010, p. 262).

Que explica o imperialismo da semiologização? A idéia fundamental aqui é que cada grupo humano deve ser encarado como uma "cultura". Isto explica que toda atividade pode ser apreendida culturalmente (JACOBY, 2001, p. 60). No entanto, Jacoby afirma que, "o conceito mais elástico de cultura serviu para combater o preconceito e o etnocentrismo" (p. 61). É aqui a base do multiculturalismo. Mas o problema é que o próprio multiculturalismo "repousa numa confusão intelectual, na recusa ou na incapacidade de entender o que forma uma cultura" (p. 61). É possível reconhecer a relevância da diversidade que resulta do processo de subjetivização da cultura, mas, devemos também admitir que "o jargão da diversidade cultural obscurece as realidades sociais e econômicos, que se tornam irrelevantes ou desinteressantes” (p. 61).

Outro problema relacionado com o tema discutido acima é que a hermenêutica compartilha uma preocupação fundamental com o estruturalismo que concede um lugar determinante ao inconsciente. $O$ signo é importante para a hermenêutica, porque ele fornece uma dica interessante para compreender as sociedades antigas e tradicionais. A 
sociedade ou a história encarada pela hermenêutica é um mundo cheio de signos. Sem nenhuma lei racional, objetiva, ele pode ser interpretado. Isto é uma crítica indireta da filosofia do Iluminismo e de Hegel e Marx. Todos ensinam que o mundo (a natureza, a sociedade, a história) é racional e inteligível pela razão humana, ao mesmo tempo, a apreensão intelectual deste mundo implica a possibilidade de sua transformação radical.

A filosofia da libertação na África e na América Latina é herdeira desta abordagem. Ela enfatiza a necessidade de compreender, com os instrumentos da razão, o real antigo ou tradicional com a intenção transformá-lo. Ora, aquele real aparece sob várias formas: ignorância, subdesenvolvimento científico e técnico (apesar da retórica ingênua e demagógica sobre a "epistemologia do sul", o "conhecimento indígena”, etc. (SANTOS, 2006; 2010), além de escravidão, violência colonial, exploração imperialista. É porque Frantz Fanon (2002), Kwame Nkrumah (1976), Aimé Césaire (1955/2004), Cheikh Anta Diop (1954;1959/1982; 1981), Marcien Towa (1971a; 1971b; 1983), Charles Romain Mbele (2010) enfatizam a necessidade absoluta de transformar o real em uma ação revolucionária.

Mas, a hermenêutica e a estética (que consideram o mundo como um conjunto de símbolos ou como um texto bom para ser interpretado) proíbem absolutamente essa abordagem. A hermenêutica e a estética não querem aprender como transgredir a ordem atual do mundo; elas não nos mostram como sair da escravidão, da servidão, da inferioridade racial, econômica e política. O essencial para elas é só a sobrevivência no meio dos mitos, dos símbolos, das tradições mortas e ultrapassadas, das culturas emasculadas e das identidades imobilizadas ou bastardas que cercam o indivíduo.

A hermenêutica e a estética não pretendem constituir um ato de rebelião; elas não querem tampouco propor um projeto global de emancipação. O essencial é a edificação, como diz Richard Rorty (1990, pp. 349-431).

Esta função ideológica da hermenêutica não é nova ou inédita. Durante a época do nazismo, e mais tarde, da Guerra fria, a hermenêutica pertenceu ao setor ideológico do esforço da guerra das ciências da mente. Na história da filosofia africana, a hermenêutica prosperou nos países onde o Ocidente abateu de maneira violenta os poderes resultantes das lutas nacionais de libertação. Foi o caso do Congo da época do ditador Mobutu, depois do assassinato do líder nacionalista Patrice Lumumba, com a ajuda das forças belgas e americanas. Favorecendo o desenvolvimento da hermenêutica nas universidades do país, o objetivo era de desintoxicar ideologicamente as elites atraídas 
pelas idéias revolucionárias em vigor ainda nos países em luta contra o colonialismo e o imperialismo: Gana, Guinea, Argélia, Egito, África do Sul, Zimbábue, Namíbia, Moçambique, Guiné Bissau e Ilhas do Cabo Verde.

Outro ponto importante: a hermenêutica coincide com a visão etnológica do mundo. A etnologia está no cerne do projeto pós-moderno em si mesmo. Aqui, ela ocupa uma posição de destaque. O significado é que a etnologia contesta de maneira radical o projeto de uma filosofia ou de uma sociologia da libertação. Michel Foucault apreende bem essa questão quando ele opõe os princípios etnológicos da norma, da regra e do sistema aos princípios sociológicos da função, do conflito e da significação (FOUCAULT, 1966, p. 371-372). A norma, a regra e o sistema remetem ao universo etnológico repetitivo das tradições, dos costumes, dos hábitos, dos usos e do conformismo social, ético e cultural. Foucault recusa os princípios sociológicos de função, de conflito e de significação que expressam as idéias de inteligibilidade do real, da liberdade e da emancipação. A função implica a ação de um sujeito da história. Dotado da razão e do sentimento, aquele sujeito desenvolve uma personalidade que o permite enfrentar as contradições do mundo e superá-las. No conflito, ele mostra a potência de sua personalidade e de seu talento, ele pode agir no mundo porque este mundo é inteligível. A etnologia aparece a Henri Lefebvre como uma filosofia da sujeição, das limitações e das restrições (LEFEBVRE, 1971/1975, p. 88).

\section{O elogio das tribos e a recusa da idéia de uma potência africana como consequências da negação da historia}

A nostalgia etnológica é a obsessão comum para os pensadores pós-coloniais. Em relação com os princípios fundamentais da etnologia colonial, uma abordagem pós-colonial coerente implica a recusa da diacronia e da história. A sincronia tem relações estreitas com a etnologia. Esta relação significa que o estado atual da sociedade reflete o estado passado. A sociedade é o que sempre foi. A etnologia não se preocupa nem com as leis do progresso histórico nem com as formas de contradições que afetam a ordem social. Compreendemos aqui porque a questão das origens e da utopia é muito sensível na era pós-moderna e póscolonial. A nostalgia etnológica está no cerne desta era.

Os pensadores africanos de tendência pós-colonial enfatizam fortemente a questão de anarquia e de topologia para recusar a autoridade absoluta da história e o imperialismo da questão das origens (EBOUSSI, 2005, pp. 9-17), a partir de uma abordagem aberta por 
Gilles Deleuze (1980). O conceito de anarquia implica um universo sem princípios, sem regras, sem fundação e sem fundamento. O pós-colonialismo herdou esta visão do pragmatismo que elogia o anti-fundacionalismo. Este último significa, de um ponto de vista cultural ou histórico ou da identidade, a ausência das raízes. Por exemplo, a perspectiva pós-colonial de Eboussi implica um mundo privado de substância e estranho à idéia de ontologia. Isso implica também a fragmentação, a flexibilidade do ser, das formas culturais e das identidades. O vazio do ser e das origens impõe a exigência de tornar relativa a questão fundamental das origens da filosofia e da própria civilização africana. Assim, o Egito que foi a grande preocupação de Cheikh Anta Diop (1954; 1981) cessa de constituir uma referência absoluta; um lugar sagrado da verdade ou da redenção histórica do negro.

Eboussi opõe à perspectiva histórica e aos princípios da fundação e das raízes o relativismo e a contingência absoluta do ser negro. Assim se explica a importância do conceito de topologia que remete ao um espaço sem limite, sem início e sem fim.

A questão da topologia decorre das doutrinas estruturais e pós-estruturais. Mas ela está presente principalmente na filosofia de Gilles Deleuze (1980). Na recusa da diacronia, o estruturalismo e o pós-estruturalismo opõem a sincronia à diacronia. A sincronia remete às características do espaço e das relações entre os objetos ou entre os indivíduos no espaço. Os elementos e os objetos em relação no espaço podem mudar, mas o movimento aqui só implica a mudança de lugar enquanto a estrutura ela mesma fica estável. O estruturalismo supõe um movimento sem mudança qualitativa, sem evolução, sem tendência ascendente e sem progresso.

Isso explica a hostilidade dos pós-coloniais contra a história, a diacronia e a gênese. A gênese implica a existência de um eixo principal genético. Ao contrario, a topologia constitui uma anti-genealogia que contesta todas as referencias à uma arché ou ao um princípio. Isso implica também a contestação radical de todas as éticas que propõe como horizonte final a celebração da Ancestralidade.

A importância na topologia não é o sentido ou a significação, mas a apreensão das linhas, ou dos estados dos objetos num espaço estrutural. A topologia implica a desterritorialização que significa uma mudança permanente dos estados e dos estatutos dos objetos e das pessoas neste espaço que se confunde com o próprio espaço da globalização. Este processo de câmbio leva ao fim dos códigos, das diferenças e das identidades. 
No contexto da filosofia africana, a topologia significa que a questão da identidade não pode ser resolvida com os argumentos da história, mas da geografia que implica a ausência de lugar privilegiado ou sagrado como, por exemplo, o Egito antigo. Os fetiches de uma grande história africana, de uma origem sagrada e do Egito como referência absoluta, ficam assim em ruínas. Surge aqui uma vez mais, a questão decisiva de Ancestralidade. A questão é cultural e política. A Ancestralidade remete ao universo dos antepassados eminentes, criadores de instituições políticas, de normas culturais, de princípios éticos, de leis científicas ou de receitas técnicas. São os heróis da cultura, da ciência, da técnica e da política que permitiram os progressos da sociedade, da cultura e da civilização. É porque eles são celebrados.

O problema é que Achille Mbembe (2000), Mamadou Diouf (1999), Jean-Godefroy Bidima (1993; 1995) e Souleymane Bachir Diagne (2007) recusam o culto dos heróis negros que lutaram para a emancipação da África sob o pretexto do "fim da historia"; eles rejeitam a referência aos lugares sagrados da África (o Egito, por exemplo) sob o pretexto da reversibilidade absoluta do espaço estrutural e da banalidade do cotidiano. O problema é que estes pensadores continuam a celebrar os heróis greco-latinos (filósofos, heróis militares, santos da Igreja) e a elogiar os lugares sagrados do mesmo Ocidente (Atenas, Roma, etc.).

Segundo uma mesma perspectiva pós-moderna já encontrada em Eboussi (2005), o pós-colonialismo celebra o tempo presente, o instante, o instantâneo ou também, a falta do tempo longo, da profundidade da história e das raízes. Ao mesmo tempo, ele elogia os tempos plurais e anárquicos das etnias contra o tempo longo e universal das nações ou das histórias nacionais. Essa celebração corresponde ao elogio dos fragmentos das nações, segundo uma perspectiva emprestada dos Estudos culturais e dos Estudos pós-coloniais que recusam o projeto global de uma história econômica, política e social (Cf. DIOUF, 1999, p. 286). Temos aqui a explicação última do conceito de tribalismo pós-moderno, encarado por Maffesoli (1992). A perspectiva pós-moderna e pós-colonial indica que o Negro é condenado a permanecer o homem tribal. Tal é o seu destino no mundo da globalização. O mundo pós-moderno e pós-colonial não conhece as classes sociais, as nações ou os estados; ele só conhece as tribos, as comunidades lingüísticas, culturais, religiosas. 


\section{Considerações Finais}

Neste estudo, vimos algumas contradições maiores que caracterizam as doutrinas que estudam a Condição Negra desde o século dezoito até a Negritude e o Póscolonialismo. Ressaltei a idéia de que a Condição atual do negro no mundo parece inseparável do destino que o capitalismo confere a cada grupo ou a cada raça. Isto explica porque o estruturalismo, a etnologia e uma tendência significativa da Negritude (senghorismo) e do pós-colonialismo censuram o "pecado historiográfico" para desenvolver uma perspectiva que torna relativa a grande história africana autônoma. O estruturalismo pode ser definido como uma ideologia do poder (LEFEBVRE, 1971/1975, p. 7). Ele reflete os objetivos operacionais do capitalismo e da superestrutura ideológica deste regime econômico e político. A etnologia é uma resposta "cultural” do capitalismo da época estrutural à questão sensível de demandas políticas das nações exploradas e oprimidas. O objetivo das filosofias da emancipação era de liberar os "primitivos" do aperto do Império em nome do progresso histórico de todos os povos. Como resposta, o estruturalismo, como ideologia do poder, propõe manter o "primitivo" na estrutura para salvar o equilíbrio do sistema. O sistema funciona bem só com seu dualismo: um norte rico e opressor por um lado, uma periferia pobre e oprimida por outro lado.

Como outra resposta às reivindicações políticas do Terceiro mundo vinculadas às questões da igualdade social, da liberdade política, da independência nacional e do progresso econômico, o estruturalismo propõe a volta à cultura primitiva e a regressão ao etnológico (LEFEBVRE, 1971/1975, p. 61). O elogio da igualdade e da diversidade das culturas implica como resultado o encontro do atual no arcaico. É assim que o estruturalismo e a etnologia propõem uma alternativa cultural ou étnica e racial à questão política de emancipação e de progresso histórico dos povos negros. A etnologia pode ser vista como uma ideologia da fragmentação social e política. Uma luta eficaz contra a opressão política, econômica e cultural necessita a aproximação das pessoas e o ajuntamento dos povos nos vastos conjuntos sociais de tipo moderno: classes sociais, partidos políticos, sindicatos, etc. Pela fragmentação social, racial, étnica, cultural e religiosa dos povos, a etnologia impede a realização de tais objectivos. $\mathrm{Na}$ África e no Terceiro mundo, um dos objetivos politícos verdadeiros dos saberes indígenas, do multiculturalismo e da teoria do tribalismo pós-moderno é de tornar impossivél a formação de uma poderosa força de oposição universal e a edificação de um grande conjunto pan- 
africano vinculado aos outros povos do mundo (inclusive os da Europa e da América do Norte), também vitimas da opressão. O relativismo cultural e a fragmentação cultural, racial e religiosa do mundo enfraquecem a luta política contra a opressão e a exploração; ao mesmo tempo, eles impedem a saída do Império e a constituição de uma força alternativa ao capitalismo opressor.

A Negritude e o Pós-colonialismo consideram o vasto Império mundial, capitalista e pós-moderno como o lugar privilegiado para o desenvolvimento do negro. Definido como mão de obra barata, mas também como consumidor dos resíduos sujos da indústria do norte, o negro é convidado a se mover dentro das estruturas sociais anãs, sob a forma das tribos isoladas, das comunidades culturais ou religiosas fechadas. O Império aparece como uma realidade contraditória. Ele favorece ao mesmo tempo o culto da particularidade e a abertura ao mundo. É necessário esclarecer que a transição do fechamento à abertura não acontece aqui de maneira dialética, porque a dialética implica uma solução radical da contradição que caracteriza a "unidade negativa" de nosso mundo atual. A dialética tem como objetivo a saída definitiva do regime do Império e a emancipação total do negro. O paradoxo é que o Império pós-moderno aparece como o lugar de coexistência incomum entre o fechamento das identidades e o hibridismo dos seres. Só mesmo as leis do mercado podem explicar este tipo de coexistência entre realidades antagonistas. As comunidades fracas e franzinas da época da globalização têm uma característica comum: são os grupos humanos e culturais onde os indivíduos estão ligados por únicos laços de consumo. Abandonado a si mesmo, o mercado é incapaz de promover o surgimento de uma autêntica cultura. $O$ que substitui a cultura é, portanto, 1. Uma forma degradada de conhecimento celebrada na teoria de saber local ou indígena; 2. Uma forma degenerada, bastarda de religiosidade que resume bem a "espiritualidade pósmoderna”. É nessa perspectiva que aparece a exigência pós-moderna de reencantamento do mundo. Com a astrologia, este último pertence à ordem da "ecologia de saberes" (SANTOS, 2006, p. 790) ou “ecologia do espírito" (MAFFESOLI, 2003, p. 70). Segundo Santos, a "ecologia de saberes permite não só superar a monocultura do saber científico, como a idéia de que os saberes não científicos são alternativos ao saber científico". Então Santos conclui que:

A ciência moderna não é a única explicação possível da realidade e não há sequer qualquer razão científica para a considerar melhor que as explicações alternativas da metafísica, da astrologia, da religião, da arte e da poesia" (SANTOS, 2010a, p. $83)$. 
$\mathrm{Na}$ África e na América Latina como na Ásia, o surgimento no domínio acadêmico da teoria de saberes indígenas permite por a tônica na questão da magia e da bruxaria em detrimento de estudo dos clássicos na literatura, na filosofia, na matemática, na ética que são as criações dos sábios do Egito antigo e da África tradicional (Cf. HEBGA, 1998).

A tarefa essencial da filosofia e da antropologia da libertação hoje é captar a energia espiritual e intelectual nessas fontes inesgotáveis da ciência e da cultura para enfrentar eficazmente os desafios de nossa época. O negro vai entrar na história como sujeito ativo pela retomada da iniciativa histórica e o trabalho da razão no mundo. A meu ver, as soluções pós-modernas baseadas na mestiçagem ou no reencantamento do mundo são um impasse absoluto; elas constituem uma armadilha viciosa para manter o negro na servidão.

A questão fundamental e urgente que a "filosofia da ancestralidade" deve resolver é a seguinte: como conciliar a desterritorialização do corpo negro, o reconhecimento da contingência e da flexibilidade de seu ser e de sua identidade, com a exigência de afirmação da Personalidade africana, condição sine qua non para sua emancipação verdadeira?

A perspectiva pós-moderna inspirada por Gilles Deleuze e Antonio Negri apresenta como pré-requisito o êxodo antropológico que implica a mudança dos corpos, o objetivo sendo a criação de novos corpos pós-humanos, capazes de resistir à dominação, à tirania da raça, da historia, da vida familiar, do regime sexual normal, do trabalho (NEGRI, 2000, p. 269).

Não tenho dúvidas de que o conceito essencial do "corpo desterritorializado" e as “Formas flutuantes" estudados por Eduardo Oliveira (2007, pp. 103-125) podem ser uma resposta possível à questão trágica do corpo negro escravizado, violado, abusado, desprezado. $\mathrm{Na}$ verdade, a perspectiva pós-moderna concebe o corpo como um "signo flutuante" ou como uma oportunidade para o processo de "mediação de uma passagem a outra” (EDUARDO, p. 114; p. 116). Como Deleuze antes, Negri percebe a desterritorialização e o êxodo antropológico como um fator de emancipação. $O$ êxodo antropológico implica também a possibilidade de simbiose com outros homens, outras raças, outras culturas (NEGRI, 2000, p. 269).

Essas respostas podem ser relevantes na perspectiva do universalismo pósmoderno. O desafio aqui é a emancipação individual e não coletiva, a questão maior sendo 
o do ajustamento e da adaptação das classes hedonistas pós-modernas às leis do consumismo.

Mas o problema do Negro como bloco histórico oprimido ou como humanidade explorada fica. Precisamos é de uma solução diferente com perspectiva da retomada da iniciativa histórica perdida na época de conquista. Isso significa a construção na África de uma grande potência política, econômica, científica, tecnológica, cultural e militar.

A mestiçagem significa que o Negro é condenado a parasitar o mundo; que ele não é um sujeito ativo de sua historia. Jean-Godefroy Bidima percebe o negro como um clandestino na História, só capaz de usar de astúcia para dar os golpes baixos ao Império e de aproveitar furtivamente (como um borlista) dos espaços livres e das oportunidades ofertadas pela globalização.

Os pensadores eminentes negros das Américas (W. Dubois, Marcus Garvey, Aimé Césaire, Franz Fanon, etc.) e da África (Kwamé Nkrumah, Cheikh Anta Diop, Marcien Towa, etc.), recusaram esta solução de mediocridade. A astúcia, o ajustamento e a política miserável de golpes, que os pós-colonialistas celebram, refletem a mentalidade dos sujeitos históricos derrotados, que desistem da luta. A perspectiva da filosofia da libertação é a ascensão da África à potência mundial, ao lado e ao mesmo nível de desenvolvimento, de poder e de responsabilidade que os outros povos do mundo: Europa, América do Norte, Ásia, América Latina; ela afirma que o negro não é um parasita ou um borlista no trem da História. A ambição da África não é permanecer no estatuto de parasita do mundo, mas de compartilhar a gestão colectiva dos assuntos do mundo moderno igualmente com outros. O pós-colonialismo confunde co-operação, intercâmbio, co-responsabilidade com gestão dos assuntos comuns à mestiçagem.

Falando desta última solução possível para o problema racial no Brasil, Cheikh Anta Diop afirma:

Eu creio que a mestiçagem biológica, a mestiçagem cultural, elevada ao nível de uma doutrina política aplicada a uma nação, é um erro que pode mesmo conduzir a resultados lamentáveis. Eu creio que todas nações devem cooperar no plano cultural, mas neste momento as expressões que empregarão são os de intercâmbio cultural, não se deve ir além e criar uma doutrina de mestiçagem cultural ou biológica. Isto pode levar, a longo prazo, a uma crise de identidade dos indivíduos e crise de identidade nacional, como parece ter ocorrido no Egito na baixa era. Chega um momento em que a nação mesma se interroga sobre sua própria identidade e se pode prosseguir mais além neste caminho para chegar aos fins que procura. Eu 
acredito que se devam deixar as relações prosseguir naturalmente e não pressionar uma mestiçagem qualquer, o que é um erro político e que nada tem a ver com uma abertura e o desenvolvimento de uma civilização multirracial (DIOP in MOORE, 2007, p. 323).

O verdadeiro problema com a mestiçagem é que a Negritude e o Pós-colonialismo não podem imaginar outra forma de presença do Negro no mundo. A mestiçagem é uma maneira de ajustamento e de submissão à ordem atual do mundo. Daí a necessidade de relançar o debate crucial aberto nos Estados Unidos pela questão da Acomodação de Atlanta (DUBOIS, 1999, pp. 93-115). A controvérsia entre Booker T. Washington e W. E. Dubois foi sobre duas visões concorrentes da Condição Negra. A visão de Washington aceita a impotência política e a inferioridade cívica do Negro em nome dos benefícios econômicos. Para Washington, a questão da igualdade social e da emancipação política é um absurdo, porque, para ele, “o negro só pode sobreviver pela submissão” (DUBOIS, p. 107). Mas a pergunta de Dubois é a seguinte:

Será possível que [...] milhões de homens possam efetivar um progresso real em termos econômicos, estando privados de direitos políticos, reduzidos a uma casta servil? (DUBOIS, p. 108).

Os pensadores pós-colonialistas deveriam responder a esta pergunta crucial, a partir do momento que eles rejeitam a questão política e cultural da luta, da emancipação, do heró́smo, da edificação de uma Potência política, industrial e militar africana moderna (Cf. MBEMBE, 2000, p. XV; BIDIMA, 1995, p. 83). A ocupação militar da Costa do Marfim pela França e a intervenção militar atual da OTAN na Líbia, mostram a urgência vital desta questão.

\section{REFERÊNCIAS BIBLIOGRÁFICAS:}

1. APPADURAI, Arjun. Après le colonialisme. Les conséquences culturelles de la Globalisation. Paris: Payot, 2001.

2. BIDIMA, Jean-Godefroy. Théorie critique et modernité africaine. De 1'Ecole de Francfort à la Docta spes africana. Paris: Publications de la Sorbonne, 1993.

3. BIDIMA, Jean-Godefroy. La philosophie africaine. Paris: PUF, 1995

4. BURKE, Peter. O que é historia cultural ? Traducão Sergio Goes de Paula. Rio de Janeiro, Zahar, 2008.

5. CESAIRE, Aimé. Discours sur le colonialisme, suivi de Discours sur la Négritude. Paris: Présence Africaine, 1955/2004.

6. COURS NOUVEAU. REVUE TRIMESTRIELLE DE STRATEGIE ET DE PROSPECTIVE. Sarkozy, la controverse de Dakar. Contexte, enjeux et nondits. $\mathrm{N}^{\circ} 1-2$, mai-octobre 2008, Dakar.

7. COUTINHO, Carlos Nelson. O estruturalismo e a miséria da razão. São Paulo: Editora Expressão Popular, 2010. 
8. DELEUZE, Gilles e GUATTARI, Félix. Capitalisme et schizophrénie 2. Mille plateaux. Paris: Editions de Minuit, 1980.

9. DIAGNE, Souleymane Bachir. (2007). Léopold Sédar Senghor : l'art africain comme philosophie. Paris: Riveneuve, 2007.

10. DIOP, Cheikh Anta. Nations nègres et culture. Paris: Présence Africaine, 1954.

11. DIOP, Cheikh Anta. L'unité culturelle de l'Afrique noire. Paris: Présence Africaine, 1959/1982.

12. DIOP, Cheikh Anta. Civilisation ou barbarie. Paris: Présence Africaine, 1981.

13. DIOP, Cheikh Anta, Entrevista, In MOORE, Carlos, Racismo e sociedade. Novas bases epistemologicas para entender o racismo. Belo Horizonte: Mazza Edicões LTDA, 2007.

14. DIOUF, Mamadou, L'Historiographie indienne en débat. Colonialisme, nationalisme et sociétés postcoloniales. Paris : Karthala/Amsterdam: Sephis, 1999.

15. DUBOIS, W. E. B. As Almas da Gente Negra, Rio de Janeiro: Lacerda Editores, 1999.

16. EBOUSSI BOULAGA, Fabien. "Anarchie et Topologie », in Relecture critique des origines de la philosophie et ses enjeux pour l'Afrique : Menaibuc: Paris, 2005.

17. ETOUNGA MANGUELE. L'Afrique a-t-elle besoin d'um programme d'ajustement culturel?. Ivry: Editions du Sud, 1993.

18. FRANTZ, FANON. Les damnées de la terre. Paris: La Découverte, 2002.

19. FOUCAULT, Michel. Les Mots et les choses: une archéologie des sciences humaines. Paris: Gallimard, 1966.

20. FROBENIUS, Leo. Le Destin des civilisations. Paris: Gallimard, 1940.

21. FROBENIUS, Leo. Histoire de la civilisation africaine. Paris: Gallimard, 1952.

22. GOBINEAU, Arthur de, 1967. Essai sur l'inégalité des races humaines. Paris: Belfond, 1967.

23. GRIEGER, Paul. La Caractérologie ethnique. Paris: PUF, 1961.

24. HEBGA, Meinrad. Rationalité d'un discours africain sur les phénomènes paranormaux. Paris: L'Harmattan, 1998.

25. HAYEK, Friedrich August Von. La Route de la servitude. Paris: Quadrige/PUF, 1985.

26. HEGEL, G.W.F. Leçons sur la philosophie de l'histoire. Paris: J. Vrin, 1970.

27. HUME, David. Essais moraux, politiques \& littéraires. Paris: Editions Alive, 1999.

28. HUNTINGTON, Samuel. Le Choc des civilisations. Paris: Odile Jacob, 1997.

29. JACOBY, Russel. O fim da utopia. Politica e cultura na era apatia. Tradução de Clóvis Marques. Rio de Janeiro-São Paulo: Editora Record, 2001.

30. KANT, Emmanuel. Observações sobre o sentimento do belo e do sublime: São Paulo: Papirus,1993 
31. LEFEBVRE, Henri. L’Idéologie structuraliste, Paris: Anthropos, 1971/1975.

32. LYOTARD, Jean-François. L'économie libidinale. Paris: Editions de Minuit, 1974.

33. MAFFESOLI, Michel. A transfiguração do politico. Porto Alegre: Sulina, 1997.

34. MAFFESOLI, Michel. Elogio da razão sensível. Petrópolis: Vozes, 1998.

35. MAFFESOLI, Michel. La part du diable. Précis de subversion postmoderne. Paris : Flammarion, 2002a.

36. MAFFESOLI, Michel. La Transfiguration du politique. La tribalisation du monde postmoderne. Paris: La Table Ronde, 2002b.

37. MAFFESOLI, Michel. $\mathbf{O}$ instante eterno. $\mathbf{O}$ retorno do trágico nas sociedades pós-modernas. São Paulo: Editora Zouk, 2003.

38. MBELE, Charles Romain. Essai sur le postcolonialisme en tant que code de 1'inégalité. Paris : Karthala/Amsterdam, 2010.

39. MBEMBE, Achille. De la postcolonie. Essai sur l'imagination politique dans l'Afrique Contemporaine. Paris: Karthala, 2000.

40. MONTESQUIEU. Do Espírito das Leis, Livro XV, cap.1 (Os Pensadores). Tradução Fernando Henrique Cardoso. São Paulo: Abril Cultural, 1979.

41. NEGRI, Antonio/HARDT Michael. Empire. Paris: Exils Editeur, 2000.

42. NKOLO FOE. Entre negritude e pós-colonial: a sátira de Dakar ou a revanche ideológica do Ocidente, in Codesria-Boletim, números 1\&2, 2008, pp. 70-75.

43. OLIVEIRA, Eduardo. Filosofia da Ancestralidade. Corpo e mito na Filosofia da Educação Brasileira. Curitiba: Editora Gráfica Popular, 2007.

44. PIAGET, Jean. Logique et connaissance. Paris: La Pléiade, Ed. Gallimard, 1967.

45. NKRUMAH, Kwamé. Le Consciencisme. Paris: Présence Africaine, 1976.

46. SALA-MOLINS, Louis Sala-Molins. L'Afrique aux Amériques : Le Code Noir espagnol. Paris : PUF, 1992.

47. SENGHOR, Léopold Sédar. Liberté I. Négritude et humanisme. Paris: Seuil, 1964.

48. SENGHOR, Léopold Sédar,. Liberté 3. Négritude et civilisation de l’Universel, Paris: Seuil, 1977.

49. SPENGLER, Oswald. L'homme et la technique. Paris: Gallimard, 1958.

50. RORTY Richard. L'Homme spéculaire, trad. Thierry Marchaise. Paris: Seuil, 1990.

51. SANTOS, Boaventura de Sousa (Org.). Conhecimento Prudente para uma Vida Decente. São Paulo : Cortez Editora, 2006.

52. SANTOS, Boaventura de Sousa. Um discurso sobre as ciências, $7^{a}$ edição. São Paulo: Editora Cortez, 2010a.

53. SANTOS, Boaventura de Sousa e MENESES, Maria Paula (Org.). Epistemologia do Sul. São Paulo: Cortez Editora, 2010b. 
54. SENGHOR, Léopold Sédar. Liberté I. Négritude et humanisme. Paris: Seuil, 1964.

55. SENGHOR, Léopold Sédar, Liberté 3. Négritude et civilisation de l'Universel. Paris, Seuil, 1977.

56. TEMPELS, Placide. La Philosophie bantoue. Paris: Présence Africaine, 1948.

57. TOWA, Marcien. Léopold Sédar Senghor: Négritude ou Servitude ? Yaoundé : CLE, 1971a

58. TOWA, Marcien, Essai sur la problématique philosophique dans 1'Afrique actuelle. Yaoundé, Editions CLE, 1971b.

59. TOWA, Marcien. Poésie de la Négritude. Approche structurale. Sherbrook: Naaman, 1983.

60. VERMEIL, Edmond. L'Allemagne contemporaine. Paris: Aubier-Montaigne, 1952, T. 1, 1952.

61. VOLTAIRE. Essai sur les moeurs et 1'esprit des nations. Paris: Garnier, 1963.

Artigo recebido em: 15/08/2011

Aprovado em: 20/09/2011 